\section{EL REAL SIGNIFICADO DE SER MORDIDO POR MURCIÉLAGOS HEMATÓFAGOS EN LAS COMUNIDADES INDÍGENAS AMAZÓNICAS DEL PERÚ}

\section{[THE REAL SIGNIFICANCE OF BEING BITTEN BY A HEMATOPHAGOUS BAT IN INDIGENOUS COMMUNITIES IN THE REMOTE PERUVIAN AMAZON]}

\author{
Jorge Gómez-Benavides,a, V. Alberto Laguna- \\ Torres $^{2, b, d}$, Sergio Recuenco ${ }^{3, a, c}$
}

Sr. Editor. La rabia tiene gran impacto en la salud pública debido a que cuando la enfermedad se manifiesta en humanos no se dispone de un tratamiento efectivo para evitar la muerte, siendo una enfermedad prevenible con vacunas.

Específicamente en el Perú, a pesar de lo esfuerzos exitosos de control de la rabia canina, la rabia humana transmitida por vampiros continúa siendo un problema de salud pública, pues se reporta brotes aislados y esporádicos desde 1975. Hasta el 25 de noviembre de 2010 se ha notificado 291 personas fallecidas por esta enfermedad, de ellos, el $48,8 \%$ se ha presentado en la selva norte del país, en la provincia de Condorcanqui del departamento de Amazonas, los más afectados fueron los menores de 15 años de edad, en las comunidades indígenas amazónicas. (Dirección General de Epidemiología, datos no publicados).

No es difícil entender la necesidad de tomar medidas drásticas para prevenir cualquier caso de rabia humana, puesto que este terminará indefectiblemente en una muerte. La vacuna para prevenir la rabia existe desde hace 125 años y las vacunas antirrábicas modernas son efectivas y seguras a costos cada vez más accesibles. Las medidas preventivas están ampliamente difundidas pero una serie de barreras impiden que las poblaciones que más las necesitan tengan acceso a ellas.

Varios son los problemas que se asocian con la presencia de casos de rabia humana, uno de ellos es la propia actividad humana, que "invade" áreas de

\footnotetext{
Dirección General de Epidemiología, Ministerio de Salud, Lima, Perú.

2 Virology Department, U.S. Naval Medical Research Center Detachment, Lima, Perú.

3 Rabies Program, Centers for Disease Control and Prevention, Atlanta, USA.

a Médico epidemiólogo; b Médico Infectólogo; ' Doctor en Salud Pública; ${ }^{\mathrm{d}}$ Doctor en Medicina Tropical.
}

Recibido: 06-12-10 Aprobado: 09-12-10 selva donde habitan estos mamíferos, exponiéndose a ellos, como ocurre en áreas de expansión agrícola en el departamento de Junín o en los lavaderos de oro en los distritos de Huepethue e Inambari en Madre de Dios y Carabaya en Puno. Esta exposición ha terminado en brotes de rabia humana como en el año 1989 y otro en 2006-7, que comprometió a trabajadores procedentes de otros departamentos, como las zonas alto-andinas de Cusco y Puno, que migran en busca de empleo temporal (1). Esta "invasión" no solamente se manifiesta habitando temporal o permanentemente estas regiones sino que también se da al construir elementos del "desarrollo humano" como carreteras, explotación de hidrocarburos y establecimientos de comunidades rurales. Todo esto daña el hábitat de los murciélagos hematófagos y aleja a las presas que les sirven de alimento, obligándolos a acercarse a los humanos y a sus animales domésticos.

Sin embargo, existe población indígena amazónica que no invadió ningún área, o por lo menos no lo hizo en los últimos 100 años. Esta población vive expuesta de manera habitual a las mordeduras de los murciélagos hematófagos debido a que sus viviendas son "abiertas" y permiten el ingreso de los vampiros ${ }^{(2)}$. Al vivir alejados de la "cultura occidental", a fin de preservar la propia, los lleva a vivir también alejados de los servicios de salud, por ello son una población excluida e inaccesible al sistema de salud, pero debe ser protegida con especial atención.

En mayo de 2010, en una visita de carácter científico a áreas rurales de la Amazonía peruana, en el departamento de Loreto, nuestro equipo encontró un alto y alarmante grado de desinformación acerca de la rabia entre los pobladores, a pesar de que el $90 \%$ había sido mordido por un murciélago hematófago $y$, según los datos recolectados, no conocía el real significado del ataque que había sufrido y tampoco sabía que debía tomar medidas iniciales tan simples como lavar la herida con agua y jabón o acudir a un centro de salud, el que además se encontraba lejos de su comunidad. El desconocimiento sobre la enfermedad y la mordedura de murciélago llega al 95\%.

Nuestro equipo encontró que en el suero de habitantes de esta población (personas no vacunadas y asintomáticas) había anticuerpos contra la rabia, lo cual indicaba exposición al virus de la rabia, probablemente a dosis subletales (3). Todo esto no solo confirma el riesgo permanente al que se encuentran expuestas las poblaciones indígenas amazónicas, sino también revela que los esfuerzos de educación y promoción de la salud todavía son seriamente insuficientes en esta extensa región del país. 
Nuestros resultados son preliminares y formarán parte de futuras investigaciones; esta grave situación evidencia la urgente necesidad de tomar medidas para prevenir y evitar más pérdidas humanas en poblaciones susceptibles.

La vacunación de la población expuesta es una solución obvia; sin embargo, hay puntos importantes a considerar para responder a la realidad geográfica de la Amazonía. Es necesario proveer recursos necesarios para mantener un equipo de vacunación por varios días en esas poblaciones alejadas, disponibilidad de embarcaciones y combustible para realizar las visitas necesarias que garanticen el acceso a las vacunas, tener los medios para mantener la cadena de frío y brindar educación permanente sobre medidas preventivas.

En este siglo y en el presente escenario de notable crecimiento económico del país, ninguna de esas condiciones debería ser un obstáculo; como médicos peruanos comprometidos con el bienestar de la población, pensamos que se debe priorizar acciones como: socializar los hallazgos, discutir los problemas, buscar soluciones y aplicarlas a fin de llegar efectivamente a nuestras poblaciones olvidadas de una vez por todas.

Nuestro conocimiento de lo que sucede nos obliga a actuar sobre este problema, debemos enfrentar la exclusión de estas poblaciones enfatizando que la comunicación, la educación y la vacunación continúan siendo las armas más eficaces para combatir este problema, sin olvidar que nuestra constitución peruana consagra el derecho a la salud para todos los peruanos, sin excepción.

\section{Conflictos de Interés}

Los autores declaran no tener conflictos de interés en la publicación de esta carta.

\section{Disclaimer}

Las opiniones y afirmaciones contenidas aquí son propias de los autores y no deben interpretarse como posición oficial o que reflejan la opinión del Ministerio de Salud del Perú, de los Centros para el Control y la Prevención de Enfermedades de los Estados Unidos (CDC), del Departamento de la Marina o del Departamento de Defensa de los Estados Unidos.

\section{REFERENCIAS BIBLIOGRÁFICAS}

1. Gomez-Benavides J, Manrique C, Passara F, Huallpa C, Laguna VA, Zamalloa $\mathbf{H}$, et al. Outbreak of human rabies in Madre de Dios and Puno, Peru, due to contact with the common vampire bat, Desmodus rotundus. Proceedings of 56th Annual Meeting of the American Society of Tropical Medicine and Hygiene. Philadelphia: American Society of Tropical Medicine and Hygiene; 2007. p.273.

2. Recuenco S, Petersen BW, Turmelle AS, Gomez J, Vargas I, Palmer D, et al. Defining rabies in the Amazon: modeling emerging scenarios. In: XXI Conference rabies in the Americas-RITA; 2010 Oct 17-22; Guadalajara, Mexico. Guadalajara: RITA; 2010.

3. Petersen BW, Turmelle AS, Ellison JA, Recuenco S, Gomez J, Vargas I, et al. Exposure to vampire bats and rabies in two communities in the Peruvian Amazon. In: XXI Conference rabies in the Americas-RITA; 2010 Oct 17-22; Guadalajara, Mexico. Guadalajara: RITA; 2010.
Correspondencia: Jorge L. Gómez Benavides Dirección: Calle Daniel Olaechea 199, Lima 11, Perú. Teléfono: (511) 433-5859

Correo electrónico: jgomez@dge.gob.pe 